\title{
Systematic manipulation of glutathione metabolism in Escherichia coli for improved glutathione production
}

\author{
Jing Zhang ${ }^{1}$, Cong Quan ${ }^{1}$, Cheng Wang ${ }^{1}$, Hui Wu ${ }^{1 *}$, Zhimin Li ${ }^{1}{ }^{1 *}$ and Qin Ye
}

\begin{abstract}
Background: L-glutathione (GSH) is a non-protein thiol compound with important biological properties and is widely used in pharmaceutical, food, cosmetic and health products. The cellular GSH is determined by the activity and characteristic of GSH-synthesizing enzymes, energy and precursor supply, and degradation of formed GSH.

Results: In this study, genes encoding enzymes related to the precursor amino acid degradation and glycogen formation as well as GSH degradation were systematically manipulated in Escherichia coli strains over-expressing gshF from Actinobacillus succinogenes. The manipulation included disrupting the precursor degradation pathways (tnaA and sdaA), eliminating L-glutathione degradation (ggt and pepT), and manipulating the intracellular ATP level (disruption of $g(g B)$. However the constructed mutants showed lower levels of GshF expression. 2-D electrophoresis was performed to elucidate the reasons for this discrepancy, and the results indicated obvious changes in central metabolism and amino acid metabolism in the penta-mutant. Fed-batch culture of the penta-mutant ZJ12345 was performed where the GshF expression level was enhanced, and both the GSH production $(19.10 \mathrm{mM})$ and the yield based on added L-cysteine $(0.76 \mathrm{mmol} / \mathrm{mmol})$ were significantly increased.
\end{abstract}

Conclusion: By interrupting the degradation pathways of L-cysteine, serine and GSH and blocking glycogen formation, the GSH production efficiency was significantly improved.

Keywords: Escherichia coli, Glutathione, Systematic manipulation, Bifunctional glutathione synthetase, Fed-batch fermentation

\section{Background}

L-glutathione ( $\gamma$-glutamyl-L-cysteinylglycine, GSH) is a tripeptide that is the most abundant non-protein thiol in animals, plants, and microorganisms [1]. Owing to its important physiological properties e.g., as an antioxidant and detoxifier [2-4], GSH has been widely used in health foods, pharmaceuticals, and cosmetics industries [5]. In recent years, the commercial demand for glutathione has shown a generally increasing trend.

GSH can be synthesized in different microorganisms; however, the yield and productivity are usually quite low. Therefore, strain development and bioprocess

\footnotetext{
${ }^{*}$ Correspondence: hwu@ecust.edu.cn; lizm@ecust.edu.cn

1 State Key Laboratory of Bioreactor Engineering, East China University of Science and Technology, 130 Meilong Road, Shanghai 200237, China Full list of author information is available at the end of the article
}

optimization are consequently required for the improvement of GSH biosynthesis. GSH biosynthesis is generally performed by two consecutive ATP-consuming reactions catalyzed by $\gamma$-glutamylcysteine synthetase ( $\gamma$-GCS, GSHI) and glutathione synthetase (GS, GSHI) from three precursors in microorganisms: L-glutamate, L-cysteine, and glycine [1]. Combining the over-expression of endogenous or exogenous $\gamma$-GCS and GS can effectively increase GSH synthesis [6]. However, the inhibition of $\gamma$-GCS activity by GSH is of physiological significance [7] and is the rate-limiting step in GSH biosynthesis. These features greatly limit GSH accumulation. A great deal of effort has been focused on releasing the feedback inhibition caused by GSH. Murata and Kimura [8] screened an E. coli mutant in which GSH I was desensitized to feedback inhibition by GSH. When 
the desensitized GSH I-encoding gene $g s h A^{*}$ was cloned, the activity of the mutant GSH I increased tenfold compared with the wild type enzyme. Additionally, the intracellular GSH concentration of the strain carrying the mutant GSH I was 1.3-fold higher than that of the control [8]. The method of two-stage reaction was also adopted to release the feedback inhibition of GSH I caused by glutathione, and under the optimized condition, commercially available baker's yeast produced $3.44 \mathrm{~g} / \mathrm{L}$ of glutathione in $30 \mathrm{~h}$ [9]. A novel enzyme (the bifunctional glutathione synthetase encoded by $g s h F$ ) that possessed both $\gamma$-GCS and GS activities and was non-sensitive to GSH was discovered in several microorganisms, including Streptococcus agalactiae [10], Enterococcus faecalis [10], Listeria monocytogenes [11], and Streptococcus thermophiles [12]. The concentration of GSH produced by $E$. coli over-expressing gshF from $S$. thermophiles reached $11.1 \mathrm{~g} / \mathrm{L}$ [12].

Since GSH synthesis contained two ATP-consuming reactions, the supplement of ATP became one of the major factors which affected the GSH production. The glycolytic pathway of Saccharomyces cerevisiae was considered to be the intracellular ATP regeneration system for GSH synthesis [13]. A coupled system composed of recombinant $E$. coli and $S$. cerevisiae was also used to produce GSH [14]. While the efficiency of ATP utilization was still low compared to the single yeast system. Yoshida et al. [15] reported the enzymatic GSH production using metabolic engineered $S$. cerevisiae which disrupted the ATP consuming glucose-glycogen bypass pathway. The mutant achieved 3.1-fold higher ATP-generating activity and 1.7-fold higher GSH productivity compared with the control strain.

With the development of genetic engineering, some genetic modification was conducted on the host for a higher production. The previous studies were focus on improving the activity of the GSH biosynthesis system itself [16]. However the degradation of GSH is a crucial reason for the low efficiency of GSH production and this greatly inhibits the commercial of GSH. Lin et al. [17] reported the key enzymes responding to GSH degradation in E. coli with the purpose of improving GSH production. The results suggest the $\gamma$-glutamyltranspeptidase (GGT) and tripeptidase (PepT) were the key enzymes of GSH degradation and finally there has no degradation was observed in the GSH synthesis by the mutant, which is disrupted pepT and cultured at $30^{\circ} \mathrm{C}$ for $3 \mathrm{~h}$ and $42{ }^{\circ} \mathrm{C}$ for $5 \mathrm{~h}$.

Pathways for the biosynthesis of secondary metabolites use precursors synthesizes during glycolysis, the tricarboxylic acid cycle and the pentose-phosphate pathway [18]. Supply of these precursors might become one of the bottlenecks of the secondary metabolite biosynthesis.
The precursors of GSH synthesis are come from the central metabolic pathway and increase the efficiency of precursors can be another way to increase the production. However there has no report about increase the GSH production by modification of the precursor pathway. In addition, the GSH yield based on L-cysteine is critical for the industrial GSH production due to the high price of L-cysteine. There has many researches about increasing the production of L-cysteine, such as reduced the degradation of $\mathrm{L}$-cysteine by disrupting the L-cysteine degradation genes [19] or overexpressed the L-cysteine synthetases to increase the L-cysteine concentration [20, 21]. In this work, the L-cysteine degradation gene was disrupted to investigate its effects on GSH synthesis.

Recently, a newly founded bifunctional enzyme GshF from Actinobacillus succinogenes had be discovered in our lab. In this study, we investigated an E. coli strain over-expressing the gsh F from $A$. succinogenes. Systematic metabolic engineering strategies were applied in E. coli to investigate their effects on GSH production, including the reduction of $\mathrm{L}$-cysteine degradation, manipulation of the glucose storage pathway, and elimination of the biological degradation of GSH (Fig. 1). The performances of the engineered $E$. coli strains were investigated and compared with the original strain in fed-batch cultivation in a 5-L bioreactor. Because the deletion of genes can affect protein expression, the proteomes of wild type MG1655 and its mutant with a penta-gene deletion were also investigated.

\section{Results and discussion}

\section{Effect of tnaA knockout on L-cysteine degradation}

GSH is synthesized from three amino acids (L-glutamate, glycine and L-cysteine). Among them, L-cysteine is the most expensive and accounts for the major cost in GSH production. Reducing L-cysteine degradation in E. coli is beneficial for increasing the availability of L-cysteine for GSH synthesis. The cysteine desulfhydrase (CD) catalyzes the degradation of L-cysteine, and two cysteine desulfhydrases, tryptophanase encoded by tna $A$ and cystathionine $\beta$-lyase encoded by $m e t C$ ), are mainly responsible for the L-cysteine degradation in E. coli [19]. The key degradation gene tna $A$ was first interrupted in E. coli MG1655 to obtain the mutant strain MG001, and the L-cysteine degradation ability was compared with the wild type strain (Fig. 2). When MG001 was incubated with $80 \mathrm{mg} / \mathrm{L} \mathrm{L}$-cysteine for $2 \mathrm{~h}$, the residual amount of L-cysteine was $65.76 \pm 1.95 \mathrm{mg} / \mathrm{L}(82.2 \pm 0.02 \%$ of the initial amount). In contrast, the residual L-cysteine dropped to $16.54 \pm 2.55 \mathrm{mg} / \mathrm{L}$ for the wild type strain. Thus, the amount of L-cysteine degraded by the wild type strain was 4.46 -fold higher than that degraded by MG001. The result showed that the disruption of tnaA 


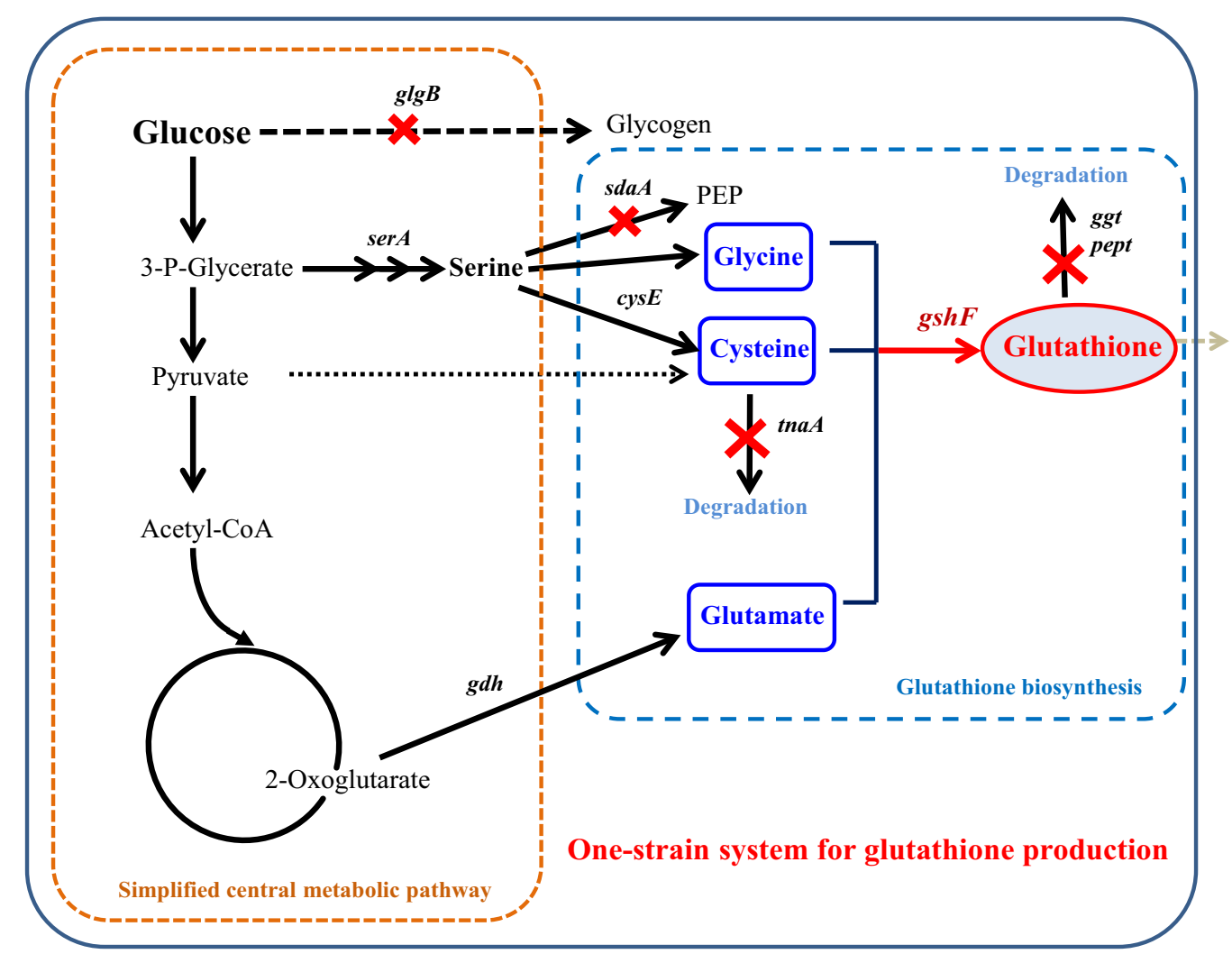

Fig. 1 Metabolic pathways of Escherichia coli for GSH production, including the pathways related to central carbon metabolism, precursor amino acid production, and GSH degradation. glgB glycogen-branching enzyme, serA D-3-phosphoglycerate dehydrogenase, cysE serine acyltransferase, sdaA L-serine deaminase, thaA cysteine desulfhydrase, gdh glutamate dehydrogenase, ggt $\gamma$-glutamyltranspeptidase, pept tripeptidase, gshF glutathione synthetase

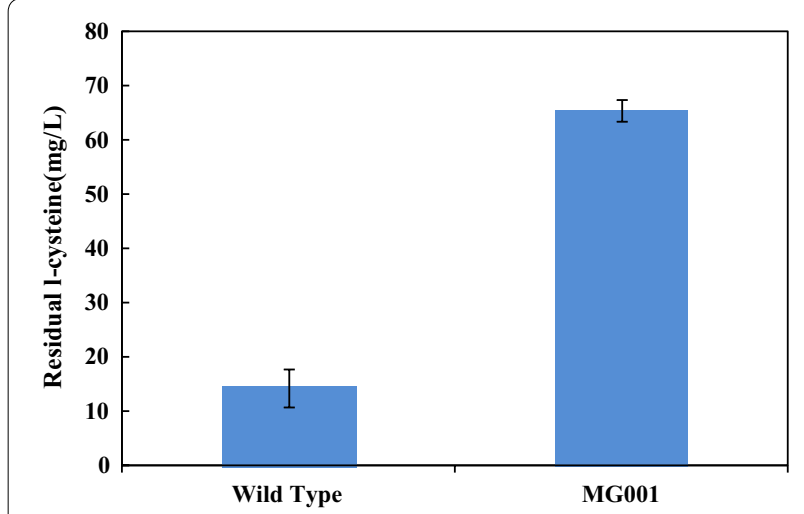

Fig. 2 The residual L-cysteine concentrations in the mutant and wild type strains after $2 \mathrm{~h}$ of incubation

significantly reduced the degradation of $\mathrm{L}$-cysteine as expected. However, the degradation of L-cysteine was not eliminated completely due to the activities of other cysteine desulfhydrases in E. coli, such as cystathionine $\beta$-lyase (CBL, encoded by metC). The other additional proteins including O-acetylserine sulfhydrylase-A,
$\mathrm{O}$-acetylserine sulfhydrylase- $\mathrm{B}$, and MalY were also identified to have L-cysteine desulfhydrase activity [22].

\section{Effect of the interruption of $g g t$ and pepT on GSH degradation}

Previous studies have indicated that GSH is significantly degraded close to the end of the fermentation process, resulting in a lower GSH production level. The key enzymes related to GSH degradation include $\gamma$-glutamyltranspeptidase encoded by $g g t$ and tripeptidase encoded by pepT; and the inactivation of GGT and PepT activities can effectively reduce the degradation of GSH in E. coli [17]. The GGT deletion strategy was also adopted in an $S$. cerevisiae strain over-expressing GCS and GS, resulting in a 1.7 -fold increase in GSH accumulation [15]. Single ggt or pepT deletion and a double deletion were conducted, obtaining the mutants MG003, MG004 and MG034, respectively. To investigate the effect of the deletion of these genes on the degradation of GSH, E. coli MG1655 and its mutants were incubated with $10 \mathrm{mM} \mathrm{GSH}$ at $37{ }^{\circ} \mathrm{C}$ for $2 \mathrm{~h}$; the results are shown in Fig. 3. Among these four strains, the highest 


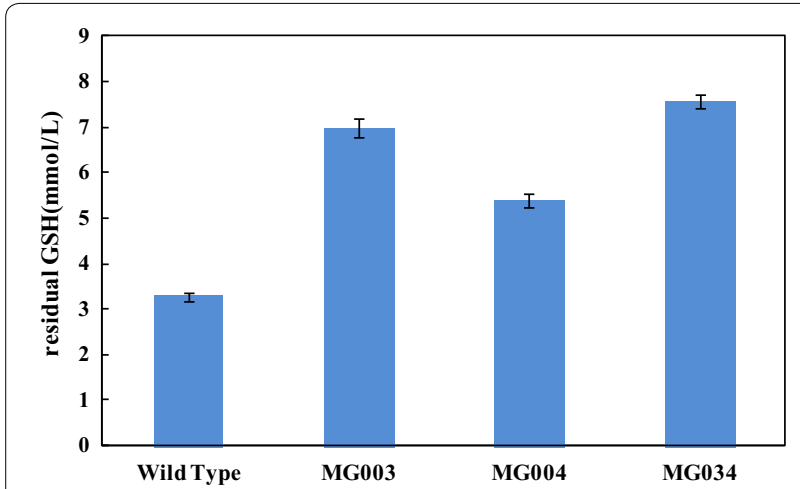

Fig. 3 The residual GSH concentrations in the mutants and wild type strains after $2 \mathrm{~h}$ of incubation

concentration of the residual GSH was $7.6 \pm 0.14 \mathrm{mM}$ in MG034 ( $\triangle g g t, \Delta p e p T)$, which was 2.4-fold that of the control (E. coli MG1655). The residual GSH concentration in MG003 was also high $(6.9 \pm 0.20 \mathrm{mM})$, which was 2.1fold that of in E. coli MG1655. These results suggested that GGT was the most important enzyme responsible for GSH degradation and that deletion of both $g g t$ and $p e p T$ could significantly suppress the GSH degradation.

\section{Manipulation of the energy supply}

GSH synthesis is an energy intensive process because the formation of $1 \mathrm{~mol}$ of GSH requires $2 \mathrm{~mol}$ of ATP. However, the efficiency of the ATP supply or utilization for GSH production seems to be very low because only $0.5 \%$ of the total ATP regenerated in the glycolytic pathway is used for GSH production under anaerobic conditions [13]. To improve GSH productivity, we attempted to direct the flux of glucose to the glycolytic pathway to benefit ATP regeneration by inactivating the glycogen generation pathway. The biosynthesis of glycogen from glucose is catalyzed by three enzymes: glycogenin glucosyltransferases, glycogen synthase, and glycogenbranching enzyme (GBE). This pathway is controlled by GBE [23-25]. Yoshida et al. reported that an engineered S. cerevisiae in which the ATP consuming glucose-glycogen bypass pathway had been shut-down by deletion of the GBE achieved 3.1-fold higher ATP-generating activity and 1.7-fold higher GSH productivity compared with the control strain [15]. In this work deletion of $\operatorname{glg} B$ encoding GBE was expected to shut down glycogen accumulation. Therefore, the mutant strain MG005 was constructed by interrupting the $g l g B$ gene in E. coli MG1655. To determine whether this mutation affected the intracellular ATP content, the ATP pool was quantified and compared to MG1655 cultured in M9 medium (Fig. 4). The ATP content in MG005 was 16-18 \% higher compared to the control, which was in agreement with the previous study [15]. The results confirmed that the deletion of $\operatorname{glg} B$

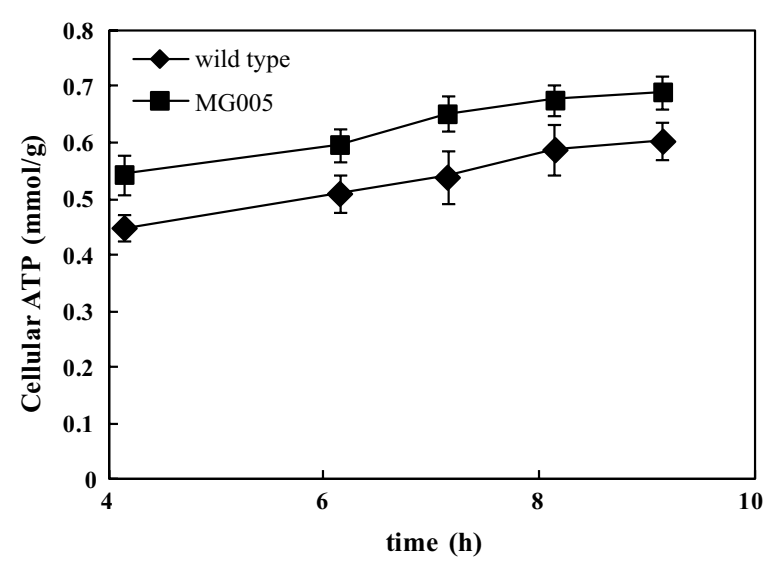

Fig. 4 Effect of the glgB knockout on the concentration of intracellular ATP in E. coli during cultivation

effectively reduced ATP and carbon consumption for glycogen accumulation.

ATP is an important cofactor of GSH production. Yeast was applied to GSH production to take advantage of its strong ability for ATP regeneration through the EMP pathway [13]. A coupled system composed of recombinant E. coli and S. cerevisiae was also used to produce GSH [14]; however, the efficiency of ATP utilization was still low compared to the single yeast system. Because the transfer of ATP formed in S. cerevisiae to recombinant $E$. coli is difficult, the cooperation between ATP generation and glutathione synthesis seemed to be inefficient. Murata et al. reported that the low GSH production of permeated cells immobilized using a polyacrylamide gel was caused by the low efficiency of the ATP supply: only $0.5 \%$ of the total regenerated ATP from the glycolytic pathway was actually used for GSH synthesis in E. coli [13]. Shutting-down the glucose-glycogen bypass pathway resulted in more glucose being driven into the glycolytic pathway to generate more ATP.

The irreversible transformation of adenosine to hypoxanthine is another reason for the low efficiency of ATP regeneration in GSH biosynthesis [26]. A strain with an add (encoding adenosine deaminase) mutation showed enhanced GSH production. However, Hara et al. [27] found that the deletion of add resulted in a reduced cell density due to the down-regulated tricarboxylic acid cycle. In the present study, deletion of add in MG1655 resulted in little increase in the intracellular ATP level (data not shown). Hara et al. [27] also reported that 34 out of 40 mutated genes which were related to ATP generation resulted in higher glutathione production. Therefore, it can be expected that screening more appropriate target genes can effectively increase the ATP generation efficiency for the enhanced production of GSH. 


\section{Production of GSH by the whole-cell biocatalyst}

Serine is the common precursor of L-cysteine and glycine and is derived from 3-phosphoglycerate (Fig. 1). Hence, the supply of serine is critical for the availability of both precursors. In E. coli, L-serine is deaminated by three very specific high- $\mathrm{K}_{\mathrm{m}} \mathrm{L}$-serine deaminases (L-SDs): SdaA, SdaB and TdcG [28-30]. SdaA was reported to be the gene encoding either the structural gene of L-SD that catalyzes the deamination of serine to pyruvate or a positive activator of transcription [31]. To enhance the fluxes to L-cysteine and glycine, we knocked out $s d a A$ to construct the double mutant MG012 by deletion of $s d a A$ in the tnaA mutant MG001. As mentioned above, the ggt of MG012 was deleted to form MG123 and pepT was deleted in MG123 to obtain MG1234. Finally, the strain MG12345 was constructed by deleting $g l g B$ (Table 1). Overexpression of the bifunctional L-glutathione synthetase GshF from S. thermophilus was reported to significantly enhance glutathione synthesis [12]. In this study, the newly discovered gshF of $A$. succinogenes was over-expressed in the various mutants and MG1655 by transforming them with the plasmid pTrc99a-as carrying gshF as (Table 1). The GshF was successfully expressed in the mutant strains, however, the expression levels in the mutant strains were lower than those in the control strain ZJ000 (Fig. 5). The overexpression level of the recombinant protein, GshF, seem to be affected by the deletion of these genes of the host strain.

To elucidate the capability of GSH biosynthesis in these strains, resting cells were used for GSH synthesis. The concentrations and yields of GSH based on L-cysteine for these engineered strains are shown in Fig. 6. Deletion of tnaA and sdaA (ZJ012) resulted in 13.10 and $16.70 \%$ increases in the GSH concentration and yield compared with ZJ000, respectively. These improvements were caused by the enhanced supply of precursors for GSH biosynthesis. The production and yield of GSH were increased in ZJ123 and ZJ1234 due to the decreased degradation of GSH. ZJ1234 produced the highest concentration $(16.20 \pm 0.45 \mathrm{mM})$ and yield $(0.81 \pm 0.02 \mathrm{mmol} /$ mmol) of GSH, which were 50.97 and $27.35 \%$ higher than those for ZJ000, respectively. During the experiments, the GSH produced by ZJ123, ZJ1234, and ZJ12345 did not decrease significantly, indicating that the lack of ggt and pepT prevented GSH degradation and further increased the yield. Because the whole-cell biocatalyst required the addition of ATP, we were not able to observe the effect of the $\operatorname{glgB}$ deletion on GSH synthesis. Hence,

Table 1 Strains and plasmids

\begin{tabular}{|c|c|c|}
\hline Name & Characteristic & Source \\
\hline \multicolumn{3}{|l|}{ Strain } \\
\hline MG1655 & Wild type of Escherichia coli & Laboratory collection \\
\hline MG001 & MG1655 $\triangle t n a A:: K^{2}{ }^{R}$ & This work \\
\hline MG003 & MG1655 $\Delta g g t:: K_{a n}^{R}$ & This work \\
\hline MG004 & MG1655 $\triangle p e p T:: K{ }^{R}$ & This work \\
\hline MG005 & MG1655 $\triangle g \lg B:: \operatorname{Kan}^{R}$ & \\
\hline MG012 & MG1655 $\triangle t n a A \triangle s d a A:: K_{a n}^{R}$ & This work \\
\hline MG034 & MG1655 $\Delta g g t \Delta p e p T:: \mathrm{Kan}^{\mathrm{R}}$ & This work \\
\hline MG123 & MG1655 $\triangle t n a A \triangle s d a A \Delta g g t:: \mathrm{Kan}^{\mathrm{R}}$ & This work \\
\hline MG1234 & MG1655 $\Delta t n a A \Delta s d a A \Delta g g t \Delta p e p T:: K_{a n}^{R}$ & This work \\
\hline MG12345 & MG1655 $\triangle t n a A \Delta s d a A \Delta g g t \Delta p e p T \Delta g l g B:: K{ }^{R}{ }^{R}$ & This work \\
\hline ZJ000 & MG1655 harboring pTrc99a-as & This work \\
\hline ZJ001 & MG001 harboring pTrc99a-as & This work \\
\hline ZJ012 & MG012 harboring pTrc99a-as & This work \\
\hline ZJ123 & MG123 harboring pTrc99a-as & This work \\
\hline ZJ1234 & MG1234 harboring pTrc99a-as & This work \\
\hline ZJ12345 & MG12345 harboring pTrc99a-as & This work \\
\hline \multicolumn{3}{|l|}{ Plasmid } \\
\hline pKD4 & kan cassette template, $\mathrm{Kan}^{\mathrm{R}}$ & {$[32]$} \\
\hline pKD46 & $\begin{array}{l}\lambda \text { Red recombinase under arabinose-inducible araBAD promoter, temperature-conditional } \\
\text { replicon, } \mathrm{Amp}^{\mathrm{R}}\end{array}$ & {$[32]$} \\
\hline pCP20 & FLP recombinase expression, temperature-conditional replicon, $\mathrm{Amp}^{\mathrm{R}}$ and $\mathrm{Cm}^{\mathrm{R}}$ & {$[32]$} \\
\hline pET28a-as & pET28a carries a bifunctional glutathione synthetase ( $g$ shF) from Actinobacillus succinogenes, Kan $^{R}$ & Yang et al. (to be published) \\
\hline pTrc99a & Cloning vector, $\mathrm{Amp}^{\mathrm{R}}$ & Laboratory collection \\
\hline pTrc99a-as & pTrc99a carries a bifunctional glutathione synthetase ( $g$ shF) from Actinobacillus succinogenes, Amp ${ }^{R}$ & This work \\
\hline
\end{tabular}




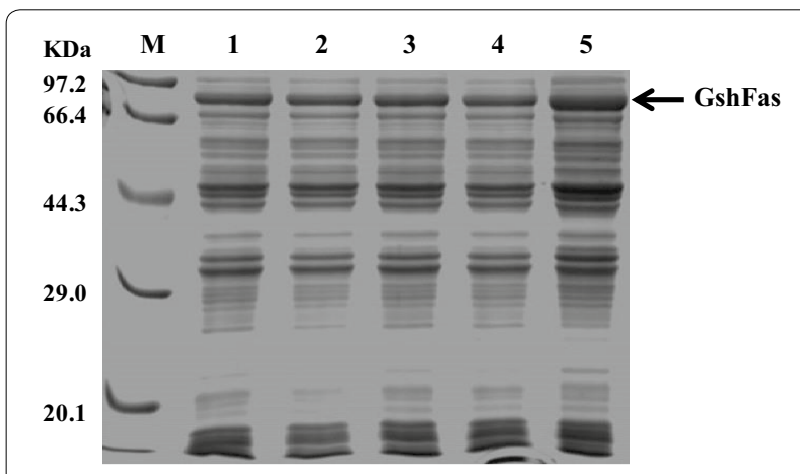

Fig. 5 Expression of the GSH synthase GshF in different hosts with different genetic backgrounds. The concentration of IPTG was $0.5 \mathrm{mM}$ and the induction time was 4 h. 1, ZJ012; 2, ZJ123; 3, ZJ1234; 4, ZJ12345, 5, ZJ000
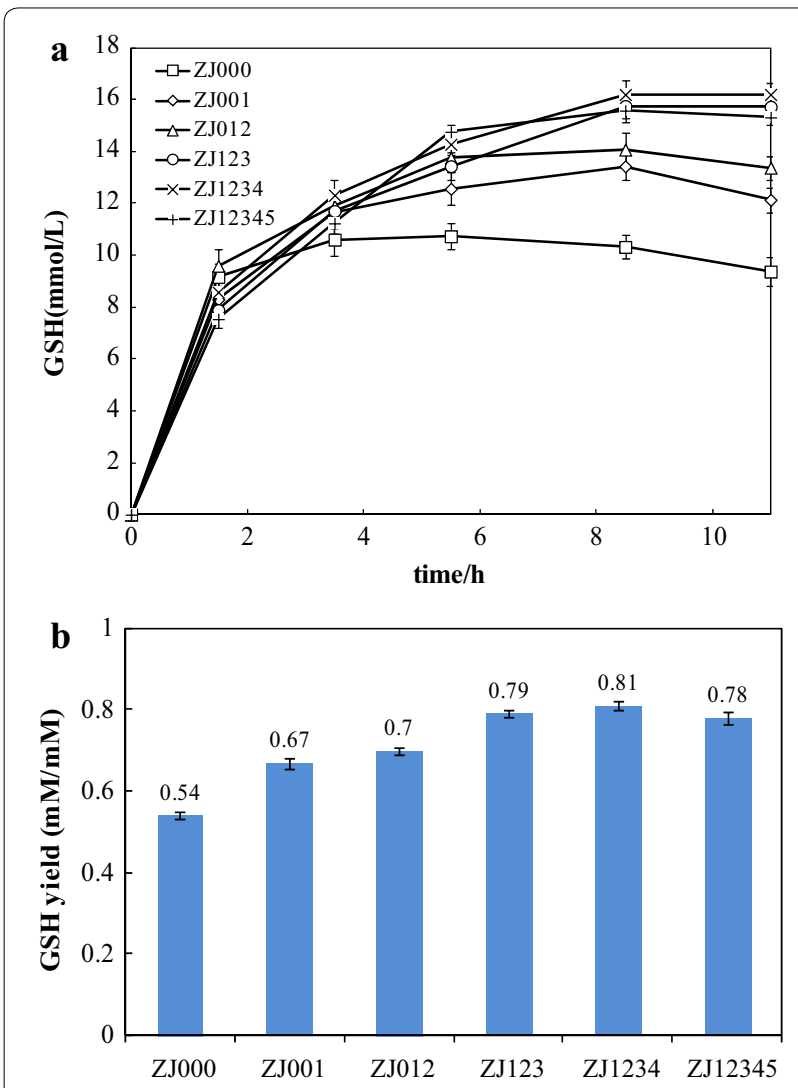

Fig. 6 The production of GSH by whole-cell biocatalyst in the engineered strains using ZJ000 as the control. a The concentration of GSH during the process; $\mathbf{b}$ the highest yield of GSH

we investigated fed-batch fermentation using glucose as the sole carbon and energy source.

Comparative proteomic analysis of MG12345 and MG1655 Although soluble GshF was expressed in all of the constructed mutant strains, the expression levels showed significant differences among these mutants following induction with the same IPTG concentration (Fig. 5). The deletion of genes can affect protein synthesis. Therefore, it would be useful to gain a global understanding of the differences in gene expression between the wild type and mutant strains.

To identify the major changes in gene expression responsible for the differences in $g s h F$ expression, we performed a proteomic study using 2-DE that compared the protein levels in MG12345 with MG1655. As shown in Table 2, 22 proteins that demonstrated significantly different expression levels were identified by mass spectrometry coupled with genome-wide analysis of E. coli. Most of the proteins were involved in central metabolism and amino acid metabolic processes. Pyruvate kinase (encoding by $p y k F$ ) catalyzes phosphoenolpyruvic acid (PEP) to form pyruvate and is a rate-limiting enzyme in the glycolysis pathway. The reduced expression of $p y k F$ in MG12345 led to an increase in the intracellular concentration of PEP and also caused an increase in the concentrations of G6P and F6P, which in turn decreased the glucose uptake rate. The increased PEP also inhibited phosphofructose kinase (encoding by $p f k$ ) activity, which was responsible for the decreased glycolytic flux and the down regulation of the glycolytic activities [33]. The expression level of pyruvate dehydrogenase (encoding by aceE), which catalyzes the reaction from pyruvate to the formation of acetyl-CoA, was only 0.13-fold in MG12345; this decrease resulted in reduced TCA cycle flux, leading to a decrease in precursors and energy for protein synthesis. Some membrane proteins, such as glutamine synthetase (encoding by $g \ln A$ ) and periplasmic putrescine binding protein (encoding by potE), are related to the transport of amino acids and can also affect the expression of proteins. Therefore, the differences in these proteins could explain the reduced expression of GshF in the mutant ZJ12345 compared to the wild type strain and help explain why the mutant required a higher IPTG concentration to obtain GshF activity similar to the wild type host strain.

\section{Production of GSH in fed-batch fermentation}

ZJ1234 and ZJ12345 were selected to produce GSH in a fed-batch culture using ZJ000 as the control strain. The inducer concentration was different for the three strains because the expression of GshF in ZJ1234 and ZJ12345 was lower than that in ZJ000 under the same induction conditions (Fig. 5). The GshF activities were similar for all three strains when the IPTG concentration was $0.5 \mathrm{mM}$ for ZJ1234 and ZJ12345 and $0.05 \mathrm{mM}$ for ZJ000. The results of the fed-batch cultures are shown in Fig. 7. The synthesis of GSH in all of these strains increased rapidly after the addition of the precursor amino acids (Fig. 7). 
Table 2 Mass spectrometry (MS) analysis of differentially expressed proteins between E. coli MG1655 and MG12345 (using MG12345 as the standard)

\begin{tabular}{|c|c|c|c|c|c|c|c|}
\hline No & $\begin{array}{l}\text { Accession } \\
\text { number }\end{array}$ & $\begin{array}{l}\text { Gene } \\
\text { name }\end{array}$ & Protein name & $\mathrm{Mr}$ & PI & $\begin{array}{l}\text { Protein sequence } \\
\text { coverage }(\%)\end{array}$ & $\begin{array}{l}\text { Difference } \\
\text { fold }\end{array}$ \\
\hline 1 & 116 & acpH & Acyl carrier protein phosphodiesterase & 22,937 & 5.53 & 46 & 37.05 \\
\hline 2 & 117 & $\operatorname{aroc}$ & Chorismate synthase & 38,520 & 5.61 & 23 & 20.71 \\
\hline 3 & 118 & pyrC & Dihydroorotase & 38,983 & 5.68 & 41 & 14.7 \\
\hline 4 & 119 & $g \ln A$ & Glutamine synthetase, type I & 51,230 & 5.27 & 44 & 0.14 \\
\hline 5 & 122 & aldA & Lactaldehyde dehydrogenase & 52,362 & 5.07 & 30 & 0.25 \\
\hline 6 & 123 & potD & $\begin{array}{l}\text { Spermidine/putrescine ABC transporter substrate- } \\
\text { binding protein }\end{array}$ & 40,899 & 5.66 & 11 & 69.67 \\
\hline 7 & 124 & $c p d B$ & $2^{\prime}, 3^{\prime}$-cyclic-nucleotide $2^{\prime}$-phosphodiesterase & 70,799 & 5.52 & 21 & 0.17 \\
\hline 8 & $\jmath 1$ & $d p p A$ & Periplasmic dipeptide transport protein & 60,483 & 6.36 & 28 & 0.11 \\
\hline 9 & $\mathrm{~J} 2$ & aceE & Pyruvate dehydrogenase & 62,256 & 5.86 & 26 & 7.39 \\
\hline 10 & $J 3$ & $\operatorname{gadA}$ & Glutamate decarboxylase alpha & 55,736 & 5.37 & 26 & 7.01 \\
\hline 11 & $J 5$ & talB & Transaldolase & 35,838 & 5.75 & 31 & 15.65 \\
\hline 12 & J6 & $d a p D$ & $\begin{array}{l}\text { 2,3,4,5-tetrahydropyridine-2,6-dicarboxylate } \mathrm{N} \text {-succinyl- } \\
\text { transferase }\end{array}$ & $-30,045$ & 5.56 & 47 & 0.023 \\
\hline 13 & J8 & menB & Naphthoate synthase & 32,737 & 6.32 & 25 & 57.61 \\
\hline 14 & 19 & $g / m M$ & Phosphoglucosamine mutase & 47,830 & 5.61 & 25 & 32.56 \\
\hline 15 & J10 & $m r p$ & Mrp protein & 41,222 & 6.05 & 19 & 10.05 \\
\hline 16 & $J 11$ & $g l p Q$ & Periplasmic Glycerophosphodiester Phosphodiesterase & 40,617 & 5.35 & 32 & 0.156 \\
\hline 17 & $\mathrm{~J} 12$ & potE & Periplasmic putrescine binding protein & 40,900 & 5.67 & 18 & 0.09 \\
\hline 18 & J13 & $a p h$ & Aminoglycoside $3^{\prime}$-phosphotransferase & 29,315 & 4.64 & 62 & 9.45 \\
\hline 19 & J15 & pykF & Pyruvate kinase I & 50,675 & 5.77 & 26 & 5.86 \\
\hline 20 & J16 & $\operatorname{aspA}$ & Aspartate ammonia-lyase & 52,920 & 5.25 & 12 & 0.055 \\
\hline 21 & $\mathrm{J17}$ & $\operatorname{tnaA}$ & Tryptophanase & 53,081 & 6 & 21 & 12.36 \\
\hline 22 & J19 & oppA & Periplasmic oligopeptide-binding protein & 46,735 & 5.5 & 39 & 0.02 \\
\hline
\end{tabular}

The final concentrations of GSH for ZJ1234 and ZJ12345 reached $17.74 \mathrm{mM}(5.45 \mathrm{~g} / \mathrm{L})$ and $19.10 \mathrm{mM}(5.87 \mathrm{~g} / \mathrm{L})$, respectively, compared with $14.32 \mathrm{mM}(4.40 \mathrm{~g} / \mathrm{L})$ for ZJ000 (Fig. 7). The yields based on the added L-cysteine were 0.71 and $0.76 \mathrm{mmol} / \mathrm{mmol}$ for ZJ1234 and ZJ12345, which were 13.68 and $18.73 \%$ higher than that for ZJ000, respectively. The GSH concentration rapidly decreased at the end of the fed-batch culture of ZJ000, while no GSH degradation occurred for ZJ1234 and ZJ12345. These results were due to the deletion of $g g t$ and pepT, which decreased the degradation of GSH; moreover, the GSH production by ZJ12345 was $7.71 \%$ higher than that by ZJ1234. In contrast to the experiments using resting cells where ATP was added into the reaction system, the higher GSH production and yield in the fed-batch cultures of ZJ124345 compared to ZJ1234 indicated that the deletion of $\operatorname{glg} B$ led to an improved ATP supply ability.

\section{Conclusions}

In conclusion, the production of GSH in E. coli was improved by the modification of metabolic pathways, including the reduction of L-cysteine degradation, manipulation of the glucose storage pathway, and elimination of the biological degradation of GSH. Deletion of the precursor degradation genes reduced the degradation significantly and the production of GSH in the mutant which overexpressed gshF from A. succinogenes increased by $13.10 \%$. The deletion of $g g t$ and pept further increased the production of GSH, and the yield reached to $0.81 \mathrm{mmol} / \mathrm{mmol}$, which is $27.35 \%$ higher than that for ZJ000. In the end, the glgb encoding the glycogenbranching enzyme was disrupted for a higher energy supplement. The penta-mutant ZJ12345 was constructed successfully, and the production of GSH was $19.10 \mathrm{mM}$ in fed-batch fermentation, which was 1.33-fold the production of MG1655 expressing the same gene. This improvement of production should help industrial glutathione production because of the higher yield and reduced degradation of product.

\section{Methods}

Strains, plasmids and molecular biology methods

All the strains and plasmids used in this study are listed in Table 1. The wild type E. coli strain MG1655 was used as the starting strain to implement metabolic engineering. Gene knockout was performed using the one-step 


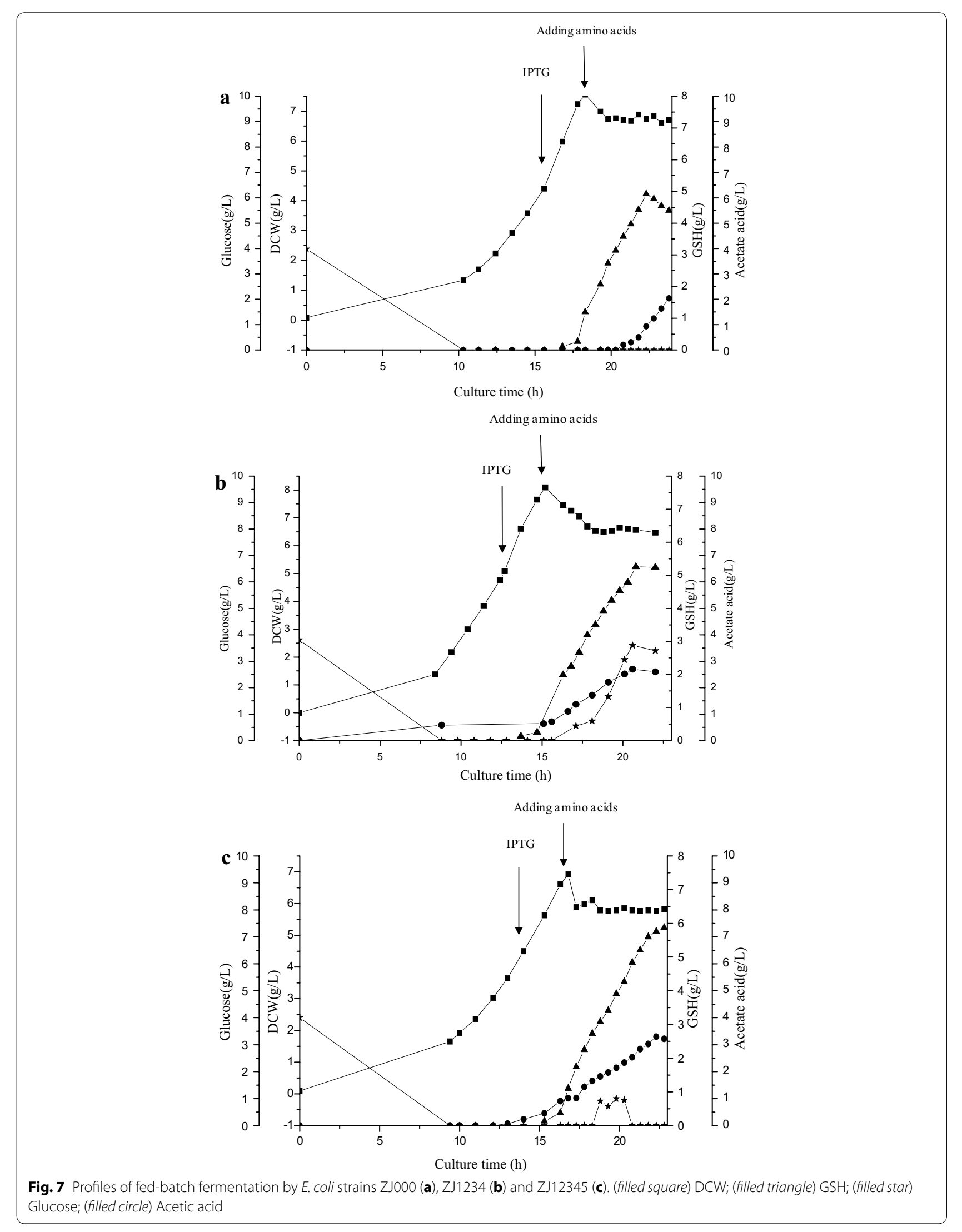


inactivation method of Datsenko and Wanner [32]. The primers for PCR are listed in Table 3. The gene deleted in a mutant was marked with a number in the name of the constructed strain (Table 1). To create the tnaA mutant, the DNA fragment containing the kanamycin resistance cassette for homologous recombination was amplified by PCR using the primers F-tnaA-FRT and R-tnaA-FRT and the plasmid pKD4 as the template. The insertion was confirmed by PCR using the primers F-tnaA-check

Table 3 Primers used in this study

\begin{tabular}{|c|c|}
\hline Primer & Sequence $\left(5^{\prime}-3^{\prime}\right)$ \\
\hline F-as & GCCGGAGCTCATGAATTTACGGCATATTAT \\
\hline R-as & CGCTCTGCAGTCATGCATTTAATAATTCCG \\
\hline \multirow[t]{2}{*}{ F-tnaA-FRT } & $\begin{array}{l}\text { ATGGAAAACTTTAAACATCTCCCTGAACCGTTCCGCATTCGT } \\
\text { GTTATTG }\end{array}$ \\
\hline & AGTGTAGGCTG GAGCTGCTTC \\
\hline \multirow[t]{2}{*}{ R-tnaA-FRT } & TTAAACTTCT TTAAGTTTTTG CGGTGAAGTG ACGCAATACT \\
\hline & TTCGGTTCGTGTCCATATGA ATATCCTCCT \\
\hline F-tnaA-check & AAACATCTCCCTGAACCG \\
\hline R-tnaA-check & GTTTTGCGGTGAAGTGAC \\
\hline \multirow[t]{2}{*}{ F-sdaA-FRT } & $\begin{array}{l}\text { GTGATTAGTCTATTCGACATGTTTAAGGTGGGGATTGGTCCC } \\
\text { TCATCTTC }\end{array}$ \\
\hline & CGTCTTGAGCGATTGTGTAG \\
\hline \multirow[t]{2}{*}{ R-sdaA-FRT } & $\begin{array}{l}\text { TTAGTCACACTGGACTTTGATTGCCAGACCACCGCGTGAGG } \\
\text { TTTCGCGGT }\end{array}$ \\
\hline & GATGTAACGCACTGAGAAGC \\
\hline F-sdaA-check & TGGGGATTGGTCCCTCATCT \\
\hline R-sdaA-check & GACTTTGATTGCCAGACCACC \\
\hline \multirow[t]{2}{*}{ F-ggt-FRT } & $\begin{array}{l}\text { TGGACGCCACTGCCACTCAGGTGGGGGTGGATATTCTCAAG } \\
\text { GAGGGCGGG }\end{array}$ \\
\hline & CGTCTTGAGCGATTGTGTAG \\
\hline \multirow[t]{2}{*}{ R-ggt-FRT } & $\begin{array}{l}\text { AACGCGGCGCATTGGTCGCTTCGGCGACGTTCAAGCCATAA } \\
\text { TCGATGCTA }\end{array}$ \\
\hline & GATGTAACGCACTGAGAAGC \\
\hline F-ggt-check & TCTGCTCTCAGGAAGTTGTT \\
\hline R-ggt-check & TAATGCTTTGTGTACTGCCC \\
\hline \multirow[t]{2}{*}{ F-pepT-FRT } & $\begin{array}{l}\text { ATGGATAAACTACTTGAGCGATTTTTGGAACTACGTGTCTCTG } \\
\text { GATACCCA }\end{array}$ \\
\hline & CGTCTTGAGCGATTGTGTAG \\
\hline \multirow[t]{2}{*}{ R-pepT-FRT } & $\begin{array}{l}\text { AATACGGACGATCACCTGCACCGCTTTTTCCATACCTTCCAG } \\
\text { AGTCACAA }\end{array}$ \\
\hline & GATGTAACGCACTGAGAAGC \\
\hline F-pepT-check & TGGATAAACTACTTGAGCGA \\
\hline R-pepT-check & TTTTCCATACCTTCCAGAGT \\
\hline \multirow[t]{2}{*}{$\mathrm{F}-\mathrm{glg} B-\mathrm{FRT}$} & $\begin{array}{l}\text { ATGTCCGATCGTATCGATAGAGACGTGATTAACGCGCTAATT } \\
\text { GCAGGCCA }\end{array}$ \\
\hline & ACGTCTTGAGCGATTGTG \\
\hline \multirow[t]{2}{*}{ R-glgB-FRT } & $\begin{array}{l}\text { AGTAAGACGGAGGGCTTGGTCGGTCTATCACCGGTCGCCAC } \\
\text { CATCGCAGT }\end{array}$ \\
\hline & ATGTAACGCACTGAGAAGC \\
\hline F-glgB-check & TCGTCAACTGGCGTAATCT \\
\hline R-glgB-check & CAGCAGCGGGTTATCTTTT \\
\hline
\end{tabular}

and R-tnaA-check listed in Table 3. Deletion of the genes $s d a A, g g t$, pepT and $g l g B$ was performed similarly.

To construct the plasmid for gshF expression, the gshF of $A$. succinogenes was amplified through PCR using pET28a-as as the template. The PCR product was digested with SacI and PstI and then inserted into the sites of pTrc99a digested with the same enzymes to form the plasmid pTrc99a-as.

\section{Medium}

Luria-Bertani (LB) medium containing $10 \mathrm{~g} / \mathrm{L}$ tryptone, $5 \mathrm{~g} / \mathrm{L}$ yeast extract, and $10 \mathrm{~g} / \mathrm{L} \mathrm{NaCl}$ was used to cultivate the $E$. coli strains during strain construction. M9 minimal salt medium containing $5 \mathrm{~g} / \mathrm{L}$ glucose, $15.1 \mathrm{~g} / \mathrm{L}$ $\mathrm{Na}_{2} \mathrm{HPO}_{4}, 3 \mathrm{~g} / \mathrm{L} \mathrm{KH_{2 }} \mathrm{PO}_{4}, 0.5 \mathrm{~g} / \mathrm{L} \mathrm{NaCl}, 1 \mathrm{~g} / \mathrm{L} \mathrm{NH} \mathrm{NH}_{4} \mathrm{Cl}$, $0.5 \mathrm{~g} / \mathrm{L} \mathrm{MgSO}_{4} \cdot 7 \mathrm{H}_{2} \mathrm{O}, 0.01 \mathrm{~g} / \mathrm{L} \mathrm{CaCl}_{2}, 0.2 \mathrm{~mL} / \mathrm{L} 1 \%$ vitamin $\mathrm{B} 1$ and a $0.05 \mathrm{~mL} / \mathrm{L}$ stock solution of trace elements was used for the cultivation of engineered $E$. coli strains in different experiments for GSH production. The stock solution of trace elements contained the following in $3 \mathrm{M} \mathrm{HCl}: \mathrm{FeSO}_{4} \cdot 7 \mathrm{H}_{2} \mathrm{O} 80, \mathrm{AlCl}_{3} \cdot 6 \mathrm{H}_{2} \mathrm{O} 10, \mathrm{ZnSO}_{4} \cdot 7 \mathrm{H}_{2} \mathrm{O}$ 2.0, $\mathrm{CuCl}_{2} \cdot 2 \mathrm{H}_{2} \mathrm{O}$ 1.0, $\mathrm{NaMoO}_{4} \cdot 2 \mathrm{H}_{2} \mathrm{O} 2.0, \mathrm{MnSO}_{4} \cdot \mathrm{nH}_{2} \mathrm{O}$ $10, \mathrm{CoCl}_{2} 4.0$, and $\mathrm{H}_{3} \mathrm{BO}_{4} 0.5 \mathrm{~g} / \mathrm{L}$. An appropriate antibiotic ( $50 \mathrm{mg} / \mathrm{L}$ kanamycin or $100 \mathrm{mg} / \mathrm{L}$ ampicillin) was included in the medium when needed. For the induction of gene expression, $0.05-0.5 \mathrm{mM}$ isopropyl $\beta$-D-1thiogalactopyranoside (IPTG) was added as indicated in different experiments.

For the fed-batch culture in the 5- $\mathrm{L}$ bioreactor, medium containing $15 \mathrm{~g} / \mathrm{L} \quad \mathrm{Na}_{2} \mathrm{HPO}_{4} \cdot 12 \mathrm{H}_{2} \mathrm{O}, 3 \mathrm{~g} / \mathrm{L} \quad \mathrm{KH}_{2} \mathrm{PO}_{4}$, $0.5 \mathrm{~g} / \mathrm{L} \mathrm{NaCl}, 3 \mathrm{~g} / \mathrm{L} \quad \mathrm{NH}_{4} \mathrm{Cl}, 0.2 \mathrm{~g} / \mathrm{L} \quad \mathrm{MgSO}_{4} \cdot 7 \mathrm{H}_{2} \mathrm{O}$, $0.011 \mathrm{~g} / \mathrm{L} \mathrm{CaCl}_{2}, 0.5 \mathrm{~mL} / \mathrm{L}$ vitamin B1 $(1 \% \mathrm{w} / \mathrm{v}), 0.5 \mathrm{~mL} / \mathrm{L}$ of a stock solution of trace elements, and $4 \mathrm{~g} / \mathrm{L}$ glucose was used. The feeding medium contained $500 \mathrm{~g} / \mathrm{L}$ glucose and $25 \mathrm{~g} / \mathrm{L} \mathrm{MgSO}_{4} \cdot 7 \mathrm{H}_{2} \mathrm{O}$.

\section{Culture conditions}

The primary pre-culture was prepared by transfer of $100 \mu \mathrm{L}$ of the stock culture to $3 \mathrm{~mL}$ of LB medium. The cells were aerobically incubated at $37^{\circ} \mathrm{C}$ and $220 \mathrm{rpm}$ overnight. Then, $1 \mathrm{~mL}$ of the overnight culture was transferred into $50 \mathrm{~mL}$ of LB or M9 medium in $250 \mathrm{~mL}$ flasks for further cultivation (kanamycin or ampicillin was added when needed). An appropriate concentration of IPTG was added when the cell density reached the $\mathrm{OD}_{600}$ value of 0.4-0.6; the induction time was $2-6 \mathrm{~h}$ for the different engineered strains.

To investigate the effect of gene knockout on L-cysteine and GSH degradation, the engineered strains were cultured in the flasks as described above and the cells were collected by centrifugation $\left(6000 \mathrm{rpm}, 4{ }^{\circ} \mathrm{C}\right.$ for $\left.5 \mathrm{~min}\right)$ after two washes with $50 \mathrm{mM}$ phosphate buffer (pH7.0). Then, the cells were resuspended in $0.2 \mathrm{M}$ phosphate 
buffer (pH7.0) containing different concentrations of L-cysteine or GSH and $0.5 \%(\mathrm{v} / \mathrm{v})$ toluene, and the reaction mixture was incubated at $37^{\circ} \mathrm{C}$ for $2 \mathrm{~h}$. Samples were collected for the determination of the residual L-cysteine and GSH concentrations.

The fed-batch culture was performed in a 5-L bioreactor (NC-Bio, Shanghai, China) with the initial working volume of $2.5 \mathrm{~L}$. The primary inoculum was prepared by transferring $1 \mathrm{~mL}$ of the stock culture to $30 \mathrm{~mL}$ of $\mathrm{LB}$ medium in a $250 \mathrm{~mL}$ flask and culturing at $37^{\circ} \mathrm{C}$ for $6 \mathrm{~h}$. The primary inoculum $(1 \mathrm{~mL})$ was transferred into $140 \mathrm{~mL}$ of fresh LB medium in a $500 \mathrm{~mL}$ flask and cultured for $8 \mathrm{~h}$ to obtain the secondary inoculum, which was inoculated directly into the bioreactor. The feeding medium was continuously added into the bioreactor to obtain a constant specific growth rate $\left(0.25 \pm 0.02 \mathrm{~h}^{-1}\right)$ after the initial glucose in the medium was completely consumed. IPTG was added into the bioreactor when the concentration of the biomass reached approximately $4.5 \mathrm{~g} \mathrm{DCW} / \mathrm{L}$. After $2.5 \mathrm{~h}$ of induction, L-glutamate, glycine and L-cysteine were added into the bioreactor to concentrations of $25 \mathrm{mM}$. Before adding the precursors, the $\mathrm{pH}$ was maintained at 7.0 by automatic addition of $25 \%$ ammonia; however, $4 \mathrm{M} \mathrm{KOH}$ was used during the GSH synthesis phase. The temperature of the fed-batch culture was maintained at $37^{\circ} \mathrm{C}$.

\section{Whole-cell biocatalyst}

The GshF-overexpressing cells were obtained by centrifugation of the induced culture at $12,000 \mathrm{rpm}$ and $4{ }^{\circ} \mathrm{C}$ for $5 \mathrm{~min}$, followed by two washes with $50 \mathrm{mM}$ phosphate buffer $(\mathrm{pH} 7.0)$. The cells were stored at $-20{ }^{\circ} \mathrm{C}$ for the experiment as a catalyst. GSH synthesis using the whole-cell biocatalyst was performed in $0.2 \mathrm{M}$ phosphate buffer ( $\mathrm{pH} 7.0$ ) containing $40 \mathrm{mM}$ L-glutamate, $20 \mathrm{mM}$ L-cysteine, $40 \mathrm{mM}$ glycine, $20 \mathrm{mM} \mathrm{MgCl}_{2}$ and $20 \mathrm{mM}$ ATP. A total of $1 \mathrm{~g}$ (wet weight) of cells was added to the $10 \mathrm{~mL}$ reaction mixture, and the reaction was performed at $37^{\circ} \mathrm{C}$ and $220 \mathrm{rpm}$.

\section{Two-dimensional electrophoresis (2-DE)}

The 2-DE was performed as described by O'Farrell [34] with some modifications. The $E$. coli cells $(100 \mathrm{~mL})$ were collected $\left(6000 \mathrm{rpm}, 4{ }^{\circ} \mathrm{C}, 10 \mathrm{~min}\right)$ and resuspended in $5 \mathrm{~mL}$ of lysis buffer containing $8 \mathrm{M}$ urea, $4 \%(\mathrm{w} / \mathrm{v})$ CHAPS, and $1 \%(\mathrm{w} / \mathrm{v})$ DTT and sonicated on ice for 90 cycles (a working period of $3 \mathrm{~s}$ in a $6 \mathrm{~s}$ interval for each cycle) at a power output of $200 \mathrm{~W}$ by an ultrasonic disruptor (JY92-II, Scientz Biotechnology Co., Ningbo, China). The clear cell lysate was collected and the proteins in the supernatant were precipitated by treating with $10 \%(\mathrm{v} / \mathrm{v})$ trichloroacetic acid (TCA) on ice for $30 \mathrm{~min}$. The precipitate was collected $(6000 \mathrm{rpm}, 30 \mathrm{~min}$,
$4{ }^{\circ} \mathrm{C}$ ) and washed with $1 \mathrm{~mL}$ of acetone three times to remove the TCA. Finally, the proteins were dissolved in the same lysis buffer as described above. The concentration of soluble proteins was measured using the Coomassie Brilliant Blue method [35]. The first dimension was run essentially as described in the Amersham Biosciences manual for 2D methods [36] with some modifications. Briefly, $1 \mathrm{mg}$ of protein was added on the IPG strip (pH $4-7,24 \mathrm{~cm}$ ), and the pre-programmed power supply (EPS $3500 \times 1$, Amersham Pharmacia Biotech) was started immediately. The voltage was changed over a linear gradient from 30 to $1000 \mathrm{~V}$ over $4 \mathrm{~h}$, followed by being held at $1000 \mathrm{~V}$ for $1 \mathrm{~h}$; then, the voltage was increased linearly to $8000 \mathrm{~V}$ over $3 \mathrm{~h}$ and held at $8000 \mathrm{~V}$ for $10 \mathrm{~h}$ at $20^{\circ} \mathrm{C}$.

After completion of the isoelectric focusing, the strip was equilibrated in the equilibration solution as described by Barraclough [37] and placed on a polyacrylamide gel for SDS-PAGE with a Protean II unit (Bio-Rad, USA) at a constant voltage $(300 \mathrm{~V})$. After electrophoresis, the gel was stained with a staining solution [0.1\% coomassie brilliant blue (CBB) R250, $45 \%$ methanol, and $10 \%$ acetic acid] for $2 \mathrm{~h}$. Then, the gel was transferred to the decolorant for $2 \mathrm{~h}$. The CBB-stained gel was digitally imaged (GelDoc, Bio-Rad, USA) under UV excitation, and the image was analyzed with the software PDQuest 2D Elite. The experiment was repeated three times. Protein spots with significant differences in the knock-out strain were selected and identified using MS at Bo Yuan Bio-Tech, Shanghai, China.

\section{Analytical methods}

The cell density was estimated by measuring the optical density of an appropriately diluted culture sample at $600 \mathrm{~nm}\left(\mathrm{OD}_{600}\right)$ using a UV-7504 Spectrophotometer (Xinmao Instrument, Shanghai, China). The culture was diluted to the linear range. Dry cell weight (DCW, g/L) was calculated from the optical density according to a linear relationship between $\mathrm{OD}_{600}$ and DCW. $50 \mathrm{~mL}$ culture sample was harvested at $4{ }^{\circ} \mathrm{C}$ and $12,000 \mathrm{rpm}$ for $10 \mathrm{~min}$. The cell pellet was washed twice with deionized water, and dried at $85{ }^{\circ} \mathrm{C}$ to constant weight [38]. The optical density was converted to DCW based on a standard carve $\left(1 \mathrm{OD}_{600}=0.41 \mathrm{~g} \mathrm{DCW} / \mathrm{L}\right)$. The concentration of L-cysteine was determined by the colorimetric method described by Gaitonde [39] using the reaction with ninhydrin. The ATP concentration was measured using high performance liquid chromatography (HPLC) [40]. Proteins in the samples were precipitated by boiling or treating with $10 \%$ cold perchloric acid and then centrifuging at $4{ }^{\circ} \mathrm{C}$ and $12,000 \mathrm{rpm}$ for $10 \mathrm{~min}$. The supernatant was used for analysis. GSH was measured by HPLC (LC10AT, Shimadzu, Japan) using a WondalSil C18 column (GL Sciences Inc., Japan) and a UV detector (SPD-20A, 
Shimadzu, Japan) at $210 \mathrm{~nm}$. The column temperature was $30{ }^{\circ} \mathrm{C}$, and the mobile phase was a mixture of $\mathrm{A}$ [50 mM phosphate buffer ( $\mathrm{pH} 3.0$ ) containing $10 \mathrm{mM}$ sodium 1-heptanesulfonate] and $\mathrm{B}$ (methanol) with an A/B ratio of $95 / 5$ at a flow rate of $1 \mathrm{~mL} / \mathrm{min}$. The concentrations of glucose and acetic acid were monitored by HPLC (LC-10AT, Shimadzu, Japan) using an Amines HPX-87H column (Bio-Rad, USA) and a refractive index detector (RID-10A, Shimadzu, Japan). A mobile phase of $2.5 \mathrm{mM} \mathrm{H}_{2} \mathrm{SO}_{4}$ at a $0.5 \mathrm{~mL} / \mathrm{min}$ flow rate was used, and the column was operated at $55^{\circ} \mathrm{C}[41]$.

\begin{abstract}
Abbreviations
GSH: L-glutathione; ATP: adenosine triphosphoric acid; $Y$-GCS: Y-glutamylcysteine synthetase; GS: glutathione synthetase; GGT: Y-glutamyltranspeptidase; PepT: tripeptidase; CD: cysteine desulfhydrase; CBL: B-lyase; GBE: glycogen-branching enzyme; L-SDs: L-serine deaminases; PK: pyruvate kinase; PEP: phosphoenolpyruvic acid; G6P: glucose 6-phosphate; F6P: fructose 6-phosphate; PFK: phosphofructose kinase; IPTG: isopropyl $\beta$-D-1-thiogalactopyranoside; DCW: dry cell weight; 2-DE: two-dimensional electrophoresis; TCA: trichloroacetic acid; CBB: coomassie brilliant blue; EMP: embden meyerhof pathway.
\end{abstract}

\section{Authors' contributions}

Conceived and designed the experiments, supervision: HW ZL QY. Performed the experiments: JZ CQ CW. Analyzed the data: JZ. Contributed reagents, materials, and analysis tools: HW ZL QY. Prepared the paper: JZ HW ZL QY. All authors read and approved the final manuscript.

\section{Author details}

1 State Key Laboratory of Bioreactor Engineering, East China University of Science and Technology, 130 Meilong Road, Shanghai 200237, China. ${ }^{2}$ Shanghai Collaborative Innovation Center for Biomanufacturing Technology, 130 Meilong Road, Shanghai 200237, China.

\section{Acknowledgements \\ This study was supported by the National Science Foundation for Young Scientist of China (Grant No. 21406065), the National High Technology Research and Development Program of China (Grant Nos. 2012AA022104 and 2012AA021205), the Fundamental Research Funds for the Central Universities (Grant Nos. 222201313007 and 22A201514042), the National Special Fund for State Key Laboratory of Bioreactor Engineering (No. 2060204) and Shanghai Committee of Science and Technology (Grant No. 13DZ1930202).}

\section{Competing interests}

The authors declare that they have no competing interests.

Received: 29 October 2015 Accepted: 3 February 2016

Published online: 16 February 2016

\section{References}

1. Meister A, Anderson ME. Glutathione. Annu Rev Biochem. 1983;52:711-60.

2. Sies H. Glutathione and its role in cellular functions. Free Radic Biol Med. 1999:27(9-10):916-21.

3. Rolseth V, Djurhuus R, Svardal AM. Additive toxicity of limonene and 50\% oxygen and the role of glutathione in detoxification in human lung cells. Toxicology. 2002;170(1-2):75-88.

4. Singh RJ. Glutathione: a marker and antioxidant for aging. J Lab Clin Med. 2002;140(6):380-1.

5. Yoshida K, Hariki T, Inoue $H$, Nakamura T. External skin preparation for whitening. JP Patent. 2002;2(002):284.
6. Hara KY, Kiriyama K, Inagaki A, Nakayama H, Kondo A. Improvement of glutathione production by metabolic engineering the sulfate assimilation pathway of Saccharomyces cerevisiae. Appl Microbiol Bitechnol. 2012;94(5):1313-9.

7. Richman PG, Meister A. Regulation of gamma-glutamycystein synthetase b-nonallosteric feedback inhibition by glutathione. J Biol Chem. 1975;250(4):1422-6.

8. Murata K, Kimura A. Some properties of glutathione biosynthesis-deficient mutants of Escherichia coli B. J Gen Microbiol. 1982;128(5):1047-52

9. Li W, Li Z, Ye Q. Enzymatic synthesis of glutathione using yeast cells in two-stage reaction. Bioproc Biosystems Eng. 2010;33(6):675-82.

10. Janowiak BE, Griffith OW. Glutathione synthesis in Streptococcus agalactiae one protein accounts for $\gamma$-glutamylcysteine synthetase and glutathione synthetase activities. J Bio Chem. 2005;280(12):11829-39.

11. Gopal S, Borovok I, Ofer A, Yanku M, Cohen G, Goebel W, Kreft J, Aharonowitz Y. A multidomain fusion protein in Listeria monocytogenes catalyzes the two primary activities for glutathione biosynthesis. J Bacteriol. 2005;187(11):3839-47.

12. Li W, Li Z, Yang J, Ye Q. Production of glutathione using a bifunctional enzyme encoded by gshF from Streptococcus thermophilus expressed in Escherichia coli. J Biotechnol. 2011;154(4):261-8.

13. Murata K, Tani K, Kato J, Chibata I. Glycolytic pathway as an ATP generation system and its application to the production of glutathione and NADP. Enzy Microbial Technol. 1981;3(3):233-42.

14. Murata K. Glutathione and its derivatives: produced by recombinant Escherichia coli and Saccharomyces cerevisiae. Bioprocess Technol. 1994;19:159-83.

15. Yoshida H, Hara KY, Kiriyama K, Nakayama H, Okazaki F, Matsuda F, Ogino C, Fukuda H, Kondo A. Enzymatic glutathione production using metabolically engineered Saccharomyces cerevisiae as a whole-cell biocatalyst. Appl Microbiol Biotechnol. 2011;91(4):1001-6.

16. Li Y, Wei G, Chen J. Glutathione: a review on biotechnological production. Appl Microbiol Biotechnol. 2004;66(3):233-42.

17. Lin J, Liao X, Zhang J, Du G, Chen J. Enhancement of glutathione production with a tripeptidase-deficient recombinant Escherichia coli. J Ind Microbiol Biotechnol. 2009;36(12):1447-52.

18. Kalscheuer R, Stöveken T, Malkus U, Reichelt R, Golyshin PN, Sabirova JS, Ferrer M, Timmis KN, Steinbüchel A. Analysis of storage lipid accumulation in Alcanivorax borkumensis: evidence for alternative triacylglycerol biosynthesis routes in bacteria. J Bacteriol. 2007;189(3):918-28.

19. Awano N, Wada M, Kohdoh A, Oikawa T, Takagi H, Nakamori S. Effect of cysteine desulfhydrase gene disruption on L-cysteine overproduction in Escherichia coli. Appl Microbiol Biotechnol. 2003;62(2-3):239-43.

20. Nakamori S, Kobayashi SI, Kobayashi C, Takagi H. Overproduction of L-cysteine and L-cystine by Escherichia coli strains with a genetically altered serine acetyltransferase. Appl Environ Microbiol. 1998;64(5):1607-11.

21. Takagi H, Awano N, Kobayashi S, Noji M, Saito K, Nakamori S. Overproduction of L-cysteine and L-cystine by expression of genes for feedback inhibition-insensitive serine acetyltransferase from Arabidopsis thaliana in Escherichia coli. FEMS Microbiol Lett. 1999;179(2):453-9.

22. Awano N, Wada M, Mori H, Nakamori S, Takagi H. Identification and functional analysis of Escherichia coli cysteine desulfhydrases. Appl Environ Microbiol. 2005;71(7):4149-52.

23. Wilson WA, Hughes WE, Tomamichel W, Roach PJ. Increased glycogen storage in yeast results in less branched glycogen. Bioche Biophys Res Communi. 2004;320(2):416-23.

24. Eydallin G, Viale AM, Morán-Zorzano MT, Muñoz FJ, Montero M, BarojaFernández E, Pozueta-Romero J. Genome-wide screening of genes affecting glycogen metabolism in Escherichia coli K-12. FEBS Lett. 2007;581(16):2947-53.

25. Eydallin G, Montero M, Almagro G, Sesma MT, Viale AM, Muñoz FJ, Rahimpour M, Baroja-Fernández E, Pozueta-Romero J. Genome-wide screening of genes whose enhanced expression affects glycogen accumulation in Escherichia coli. DNA Res. 2010;17(4):61-71.

26. Liao X, Deng T, Zhu Y, Du G, Chen J. Enhancement of glutathione production by altering adenosine metabolism of Escherichia coli in a coupled ATP regeneration system with Saccharomyces cerevisiae. J Appl Microbiol. 2008;104(2):345-52. 
27. Hara KY, Shimodate $\mathrm{N}$, Ito M, Baba T, Mori H, Mori H. Systematic genomewide scanning for genes involved in ATP generation in Escherichia coli. Metab Eng. 2009;11(1):1-7.

28. Su H, Newman E. A novel L-serine deaminase activity in Escherichia coli K-12. J Bacteriol. 1991;173(8):2473-80.

29. Shao Z, Newman E. Sequencing and characterization of the $s d a B$ gene from Escherichia coli K-12. Eur J Biochem. 1993;212(3):777-84.

30. Burman JD, Harris RL, Hauton KA, Lawson DM, Sawers RG. The iron-sulfur cluster in the L-serine dehydratase TdcG from Escherichia coli is required for enzyme activity. FEBS Lett. 2004;576(3):442-4.

31. Su H, Lang B, Newman E. L-serine degradation in Escherichia coli K-12: cloning and sequencing of the sdaA gene. J Bacteriol. 1989;171(9):5095-102.

32. Datsenko KA, Wanner BL. One-step inactivation of chromosomal genes in Escherichia coli K-12 using PCR products. Proc Natl Acad Sci USA. 2000;97(12):6640-5

33. Siddiquee KAZ, Arauzo-Bravo MJ, Shimizu K. Effect of a pyruvate kinase (pykF-gene) knockout mutation on the control of gene expression and metabolic fluxes in Escherichia coli. FEMS Microbiol Lett. 2004;235(1):25-33.

34. O'Farrell PH. High resolution two-dimensional electrophoresis of proteins. J Biol Chem. 1975;250(10):4007-21.
35. Bradford MM. A rapid and sensitive method for the quantitation of microgram quantities of protein utilizing the principle of protein-dye binding. Analy Biochem. 1976;72:248-54.

36. Dumn MJ, Patel K. 2-D electrophoresis using immobilized $\mathrm{pH}$ gradients in the first dimension. Methods Mol Biol. 1988;3:201-16.

37. Barraclough D, Obenland D, Laing W, Carroll T. A general method for twodimensional protein electrophoresis of fruit samples. Postharvest Biol Technol. 2004;32(2):175-81.

38. Nikel IP, Pettinari MJ, Galvagno MA, Méndez BS. Poly(3-Hydroxybutyrate) synthesis by recombinant Escherichia coli arcA mutants in microaerobiosis. Appl Environ Microbiol. 2006;72(4):2614-20.

39. Gaitonde MK. A spectrophotometric method for the direct determination of cysteine in the presence of other naturally occurring amino acids. Biochem J. 1967;104(2):627-63.

40. Ozogul F, Taylor K, Quantick PC, Ozogul Y. A rapid HPLC-determination of ATP-related compounds and its application to herring stored under modified atmosphere. Int J Food Sci Technol. 2000;35(6):549-54.

41. Wu H, Tuli L, Bennett GN, San KY. Metabolic transistor strategy for controlling electron transfer chain activity in Escherichia coli. Metab Eng 2015;28:159-68.

\section{Submit your next manuscript to BioMed Central and we will help you at every step:}

- We accept pre-submission inquiries

- Our selector tool helps you to find the most relevant journal

- We provide round the clock customer support

- Convenient online submission

- Thorough peer review

- Inclusion in PubMed and all major indexing services

- Maximum visibility for your research

Submit your manuscript at www.biomedcentral.com/submit
() Biomed Central 